\title{
A inteligência espiritual e os raciocínios abstrato, verbal e numérico
}

\author{
Spiritual intelligence and abstract, \\ verbal and numeric reasoning
}

\author{
Katya Luciane de OLIVEIRA \\ Marina Ledier PASCALICCHIO ${ }^{2}$ \\ Ricardo PRIMI ${ }^{3}$
}

\begin{abstract}
Resumo
A presente pesquisa, que visou a explorar o tema inteligência e alguns de seus respectivos desdobramentos, foi estruturada teoricamente a partir da visão psicométrica e teve como objetivo explorar a relação entre inteligência espiritual e os raciocínios abstrato, e verbal numérico em estudantes universitários do $1^{\circ}$ e $5^{\circ}$ anos de graduação do curso de psicologia de uma universidade particular paulista. Os instrumentos utilizados foram a Bateria de Provas de Raciocínio e o Inventário de Inteligência Espiritual (PSI). A participação dos estudantes foi voluntária e a coleta de dados ocorreu de forma coletiva em uma única sessão. Os dados foram submetidos à prova de correlação de Pearson e evidenciaram uma correlação alta, negativa e significativa entre inteligência abstrata e inteligência espiritual, sobretudo nos fatores divindade $(r=-0,359, p=0,017)$ e diligência $(r=-0,414, p=0,005)$. Os dados são discutidos à luz da avaliação psicológica, numa perspectiva psicométrica, visando a elucidar algumas questões acerca do construto inteligência espiritual.
\end{abstract}

Unitermos: Avaliação psicológica. Inteligência espiritual. Universidade.

\begin{abstract}
The aim of this research was to explore the theme of intelligence and some of the respective developments. It was structured, theoretically, from a psychometric viewpoint and had the objective of exploring the relationship between spiritual intelligence and abstract, verbal and numerical reasoning in university students attending the $1^{\text {st }}$ and $5^{\text {th }}$ years of a graduate psychology course in a private university in the state of São Paulo. The instruments used were the Reasoning Test Battery and the Spiritual Intelligence Inventory. Students volunteered to take part and the data collection took place collectively in just one session. The data weresubmitted to the Pearson correlation test and evidenced a significant, negative and high correlation between abstract and spiritual intelligence, mainly in the factors of divinity $(r=-0.359, p=0.017)$ and diligence $(r=-0.414, p=0.005)$. The data were discussed in the light of the psychological evaluation from a psychometric perspective, aimed at explaining some questions about the spiritual intelligence construct.
\end{abstract}

Uniterms: Psychological evaluation. Spiritual intelligence. University.

$\nabla \nabla \nabla \nabla$

1 Universidade Estadual de Londrina, Departamento de Psicologia e Psicanálise. Rod. Celso Garcia Cid, Km 380, Caixa Postal 6001, 86051-980, Londrina, PR, Brasil. Correspondência para/Correspondence to: K.L. OLIVEIRA. E-mail: <oliveira_katya@ig.com.br>.

2 Psicóloga clínica. Atibaia, SP, Brasil.

3 Universidade São Francisco, Programa de Pós-Graduação Stricto Sensu em Psicologia. Itatiba, SP, Brasil. 
A definição do construto inteligência tem sido muito discutida entre os pesquisadores, pois não há uma definição que consiga abranger todos os desdobramentos possíveis acerca desse construto. Existem não só muitos projetos investigativos em relação a essa questão, que destacam principalmente o conceito de inteligência geral, como também perspectivas entrelaçando essas informações (Primi, 1998; Sisto, Santos \& Noronha, 2005).

De forma geral, são três as principais abordagens teóricas sobre a inteligência - a visão psicométrica de Spearman, a desenvolvimentalista de Piaget e a cognitiva de Sternberg -, conforme aponta Almeida (1988), havendo divergências dentro das respectivas correntes teóricas. Portanto, há diversas formas de entender o fenômeno, e cada pesquisador realiza sua investigação a partir da abordagem que mais se adapta aos seus pressupostos teóricos. Na presente pesquisa, a ênfase será dada à abordagem psicométrica.

Spearman (1904; 1927) desenvolveu um método para pesquisar a inteligência: a análise fatorial. Para tanto, estruturou o método da análise fatorial ao constatar que, se duas habilidades estivessem correlacionadas, ambas estariam interligadas na dependência de um elemento comum e outro específico para cada medida. Ele fez a investigação por meio de um processo estruturado e objetivo, o que possibilitou identificar esses dois fatores, e constatou, por meio desse método, que havia um fator geral, isto é, a inteligência geral presente em todas as tarefas intelectuais realizadas.

Segundo Angelini, Alves, Custódio, W. F. Duarte e L. M. Duarte (1999), Spearman identificou mais dois fatores necessários para a construção de novos instrumentos de medida: dois componentes do fator 9 , os quais chamou de Capacidade Edutiva e Capacidade Reprodutiva. Para Spearman (1904; 1927), a Capacidade Edutiva envolvia aspectos como retirar um significado de uma expressão confusa, criar novas definições, ou seja, a capacidade de ir além daquilo que está sendo percebido como aparentemente óbvio e estabelecer relações abstratas que envolvem muitas variáveis, conseguindo, assim, resolver problemas complexos. Já a Capacidade Reprodutiva seria uma atividade relacionada à capacidade de memória, isto é, a capacidade de lembrar e reproduzir aquilo que se aprendeu por 14 meios culturais que foram verbalizados. Sob essa perspectiva, Primi e Almeida (2000) apontam de desde 1942 Cattell observou a possível existência de dois fatores na inteligência, atribuindo a terminologia "inteligência fluida" e "inteligência cristalizada". A inteligência fluida tange elementos não verbais que independem de conhecimento prévio, sendo mais determinada por aspectos biológicos, e a cristalizada é desenvolvida por meio de experiências culturais e educacionais (Primi \& Almeida, 2000).

Para Primi e Almeida (2000), mais recentemente houve uma tentativa importante de integração dos conceitos de inteligência fluida e cristalizada, que se deu por meio das ideias de Carroll, Horn e Cattell - Modelo C-H-C. Nesse modelo, Horn acrescentou outras seis capacidades cognitivas: processamento visual, memória de curto prazo, armazenamento e recuperação a longo prazo, velocidade de processamento, rapidez para decisão correta, processamento auditivo.

Benzeery (2001), Gonida, Kiosseoglou e Leondari (2006) e Sailor e Abreu (2005) consideram que a inteligência é um construto muito amplo e que sua classificação é muito mais complexa no sentido de identificar com precisão as competências humanas. Os autores enfatizam que cada inteligência ou raciocínio parece ter sua própria sequência de desenvolvimento e aparece em diferentes estágios da vida.

A maioria das pessoas tem todos os tipos de inteligência ou raciocínios e o uso que se faz deles e suas diversas possibilidades de aplicação vão depender dos estímulos recebidos bem como da combinação entre fatores hereditários, ambientais e vivências. Desse modo, a inteligência é a expressão de raciocínios diferentes que, quando somados, denotam a inteligência. Primi e Almeida (2000) consideram que a inteligência pode ser constituída por cinco tipos de raciocínios: abstrato, verbal, numérico, espacial e mecânico. Cada raciocínio seria responsável por uma dada habilidade do ser humano. O abstrato se expressa na habilidade de raciocinar em situações novas, criar conceitos e compreender implicações: trata-se de um raciocínio que se associa à inteligência fluida. O verbal tange à habilidade de domínio dos conhecimentos verbal e vocabular, expressos no raciocínio utilizado em conceitos aprendidos e apresenta elementos tanto da inteligência fluida quanto da cristalizada. O numérico, por sua vez, se relaciona à inteligência fluida e à habilidade quantitativa, 
como o entendimento de conceitos quantitativos básicos, tais quais soma, subtração, multiplicação e divisão e manipulação de símbolos numéricos. Já o espacial relaciona-se à capacidade de processamento visual definida como a habilidade de representar e manipular imagens mentais. Por fim, o mecânico associa-se em parte à inteligência fluida e aos conhecimentos práticos mecânicos.

Pasquali (2005) e Primi e Ferreira (2005) discutem que há muito para se investigar sobre os raciocínios, visto que existem ainda muitos dilemas atuais da avaliação psicológica a serem elucidados. Na visão dos autores, os dilemas se concentram em torno das aparentes contradições teóricas e enfatizam que, para os avanços na área da Psicologia no Brasil, o ideal seria sintetizar os conhecimentos inerentes à inteligência de forma mais harmônica como também seria necessária uma interação entre os profissionais da área de pesquisa e os profissionais da prática psicológica. Há que se pensar no estabelecimento de uma relação de troca: os pesquisadores transformando as demandas sociais em material de pesquisa e os profissionais em consumidores críticos dos instrumentos de medidas.

Segundo Primi (2003), o grande desafio está na integração entre ciência e prática profissional. Essa missão é atribuída à área da avaliação psicológica que, por sua vez, é, muitas vezes, deturpada com uma visão equivocada de ser responsável apenas pela produção de instrumentos de medidas para psicólogos. Na realidade, é uma área que visa a explorar e operacionalizar as teorias psicológicas com um rigor científico, ou seja, torná-las observáveis por meio de um processo sistemático que permite a possibilidade de transformá-la em recurso que viabiliza o encontro entre a teoria e a prática. Dessa forma, sua missão é muito mais que fabricação de instrumentos, seu enfoque está nas teorias que visam explicar o funcionamento psicológico e, assim, contribuir com a responsabilidade esperada pela sociedade do profissional de Psicologia.

\section{Inteligência espiritual}

A relação entre a espiritualidade, a religiosidade e a saúde mental é algo que tem despertado interesse na comunidade científica, sobretudo na última década, visto que o envolvimento religioso se relaciona de forma positiva a uma saúde mental equilibrada. Há, portanto, que diferenciar os termos religiosidade e espiritualidade. O primeiro se refere a um sistema ou práticas religiosas que se focam em rituais e símbolos que servem para facilitar a crença em algo inexplicável e que recebem a denominação de Deus e suas respectivas derivações, 'força/poder maior'e 'verdade absoluta'. Já a espiritualidade abarca a questão do entendimento pessoal e singular de cada pessoa acerca de sua própria existência. Trata-se da relação dessa pessoa e o sagrado ou transcendente sem que ela tenha que necessariamente utilizar algum ritual ou símbolo (Moreira-Almeida, Lotufo Neto \& Koenig, 2006).

Sob esse aspecto, Fleck, Borges, Bolognesi e Rocha (2003) observam que os temas religiosidade e espiritualidade são tão relevantes que, em 1983, na Assembleia Mundial de Saúde, já se fomentou a possibilidade de considerar a dimensão não material e física (espiritual) ao conceito de saúde preconizado pela Organização Mundial de Saúde. Esse fato reforça a importância da espiritualidade na saúde mental.

Segundo Elias e Giglio (2001), é importante conceituar espiritualidade e diferenciá-la da religião: espiritualidade está relacionada a uma atitude, a um movimento interno, a uma expansão da consciência e a uma experiência subjetiva quando se têm pensamentos e sentimentos superiores, ou seja, ao amadurecimento da personalidade. A religião, por sua vez, se concretiza por meio de um ritual específico direcionado a atender os ensinamentos de alguma crença.

Camon et al. (2002) observam que o conceito de espiritualidade é complexo e abrangente e, devido aos seus vários desdobramentos, gera distorções relevantes ao tema. Os autores esclarecem que espiritualidade tem pouco a ver com as questões místico-religiosas: não que uma pessoa não possa desenvolver sua espiritualidade praticando alguma religião, mas trata-se de algo que vai além. O conceito abrange os determinantes que levam uma pessoa a evoluir em sua condição humana, tratando-se de uma capacidade de transcendência por meio da qual o homem busca desenvolver sua subjetividade, isto é, sua vivência interior. O termo transcendência é utilizado no sentido de buscar compreender seus limites pessoais, uma forma de se comportar perante os acontecimentos da vida, sendo uma atitude interpretativa a respeito do sentido da vida. 
Estudos internacionais (Connelly \& Light, 2003; Koenig, 2001; Koenig, Pargament \& Nielsen, 1998) revelam que as pessoas que recorrem à fé ou à espiritualidade para lidar de forma mais efetiva com quadros emocionais negativos conseguem obter resultados mais eficazes no enfrentamento de algum problema. Baptista (2004) argumenta que a questão da crença religiosa ou espiritual poderia ser um fator que promoveria uma mudança comportamental de tal modo que as pessoas ficariam impelidas a acreditar na certeza da melhora.

Embora a espiritualidade e a religiosidade constituam temas de grande relevância, há escassez de pesquisas em âmbito nacional e, principalmente, de cunho psicológico que foquem instrumentos de medidas que possam avaliar os construtos. Nessa perspectiva, Fleck et al. (2003) desenvolveram um estudo com 142 profissionais da saúde que responderam ao módulo espiritualidade, religiosidade e crenças pessoais do World Health Organization Quality of Life (WHOQOL). Um outro estudo de relevância na área foi o de Panzini e Bandeira (2005), que versou sobre a investigação da Escala de coping religioso-espiritual (escala CRE), aplicada em 616 frequentadores de instituições religiosas. Em ambos os estudos, embora os instrumentos tenham apresentado algumas evidências psicométricas, os autores ressaltam a necessidade de novas investigações, visando a um melhor entendimento dos construtos.

A interface saúde mental e religiosidade merece maiores investimentos de modo que se possa compreender a correlação existente entre as duas esferas que influenciam a vida do indivíduo. Sob esse aspecto, na última década, autores como Wolman (2001) têm averiguado a capacidade do indivíduo em atingir um objetivo social ou psicológico por meio da espiritualidade. Essa capacidade passou a ser estudada e denominada inteligência espiritual.

Wolman (2001) define a inteligência espiritual como a capacidade de transcendência que envolve diferentes habilidades, como a disposição de entrar em contato com o verdadeiro self; o investimento em atividades, eventos e relacionamentos repletos de senso altruísta e a utilização de recursos espirituais para resolver problemas na vida, ou seja, ser virtuoso e se comportar efetivamente como tal. Esses são componentes operacionais que caracterizam a inteligência espiritual.
Com a perspectiva de desenvolver um instrumento que fosse sensível para mensurar, de forma confiável, o construto inteligência espiritual, Wolman (2001) realizou um estudo que envolveu mais de seis mil homens e mulheres que responderam a um Psychomatrix Spiritiality Inventory (Inventário de Inteligência Espiritual - PSI) de 80 itens que abordava assuntos relativos à inteligência espiritual. A análise do instrumento permitiu identificar sete fatores comuns à experiência espiritual humana. O fator 1 - divindade - se refere à noção de conexão a uma figura de Deus ou a uma fonte de energia divina; o fator 2 - diligência - abarca consciência da interconexão entre corpo e mente, com ênfase em práticas que aperfeiçoam esse relacionamento; no fator 3 - intelectualidade - é possível levantar o processo cognitivo, a espiritualidade, com foco na leitura e discussão de textos sagrados; já o fator 4 - comunidade - diz respeito à qualidade de a espiritualidade estabelecer conexão com a comunidade em geral, por meio de ações como a caridade ou a política; no fator 5 - percepção extra-sensorial, é possível identificar sentimentos e percepções associados a experiências de quase-morte, sonhos, entre outros; o fator 6 - a espiritualidade na infância - analisa uma associação histórica e pessoal à espiritualidade por meio de ações e das tradições familiares. Por fim, o fator 7 - trauma - avalia o estímulo à consciência espiritual adquirida por meio de experiências com doença ou trauma, físico ou emocional, vivido pela própria pessoa ou por entes queridos. Portanto, dentro das perspectivas abordadas sobre o construto da inteligência, observa-se que a inteligência espiritual trata de mais uma habilidade, uma capacidade humana passível de ser testada pela ciência psicológica.

Antunes (2003) afirma que ainda não se pode falar em inteligência espiritual como uma capacidade específica, pois não existem pesquisas suficientes para uma indicação precisa do fenômeno. A inteligência espiritual estaria relacionada à inteligência interpessoal, aparentando ser o termo mais adequado. Trata-se da manifestação das atitudes relacionadas aos outros, da descoberta do outro e o empenho em trilhar um caminho baseado na crença espiritual.

Para Okada (1949), todos se referem à inteligência como se ela fosse única. Mas ela pode ser divina, sagrada e superior, sendo desenvolvida por meio de uma postura de fé, isto é, quando se acredita em uma força/energia 
superior. Lowen (1990) considera a espiritualidade a integração entre a mente, o corpo e a capacidade de transcendência. Quando uma pessoa está desconectada dessa capacidade, pode-se dizer que ela tornou-se um ser puramente intelectual.

Nessa direção, evidencia-se coerência ao integrar esse aspecto a uma investigação dos fenômenos psicológicos e também relevância em utilizar o instrumento abordado para verificar a suposta inteligência espiritual de Wolman (2001). Entretanto, sendo o instrumento (PSI) citado validado para outra realidade, que não a do Brasil, este estudo colocará questões e possibilidades de aplicações futuras, possibilitando novas investigações sobre o fenômeno, que parecem ser interessantes e necessárias na contemporaneidade (Baptista \& Campos, 2007). Assim, o objetivo deste estudo foi explorar a relação entre inteligência espiritual e raciocínios abstrato e verbal em estudantes universitários.

\section{Método}

\section{Participantes}

Participaram 44 estudantes universitários de uma universidade particular do Estado de São Paulo. A média de idade foi de 26 anos e 8 meses (DP=6,9). A idade mínima foi de 17 anos e a máxima de 44. Os estudantes foram divididos em dois grupos. O grupo 1 (G1) foi composto por $20(45,5 \%)$ alunos da graduação do $1^{\circ}$ ano do curso de Psicologia: 14 (70\%) do sexo feminino e 6 (30\%) do sexo masculino. O grupo 2 (G2) contou com 24 (54,5\%) alunos da graduação do $5^{\circ}$ ano do curso de Psicologia: 22 (92\%) do sexo feminino e 2 (8\%) do sexo masculino.

\section{Instrumentos}

Foram utilizados dois instrumentos:

- Bateria de Provas de Raciocínio (BPR-5), de autoria de Primi e Almeida (2000): um instrumento validado e aprovado pelo Conselho Federal de Psicologia (CFP) e o Psychomatrix Spiritiality Inventory;

- Inventário de Inteligência Espiritual (PSI), de auto-ria de Wolman (2001): ainda não apresenta evidências de validade para a realidade brasileira.
O BPR-5 é uma Bateria de Provas de Raciocínio que tem como objetivo avaliar o funcionamento cognitivo geral e algumas habilidades do indivíduo. Esse teste abrange cinco áreas específicas que são os raciocínios abstrato, verbal, espacial, numérico e mecânico. Na presente pesquisa foi aplicada a forma B (universitários) e utilizado apenas os raciocínios abstrato, verbal e numérico.

A prova de Raciocínio Abstrato (prova RA) é uma prova composta por 25 itens (19 são comuns às formas A e B) de conteúdo abstrato, envolvendo analogias com figuras geométricas. É necessário descobrir a relação existente entre os dois primeiros termos e aplicá-la ao terceiro para se identificar a quarta figura entre as cinco alternativas de respostas. O tempo limite é 12 minutos.

A prova de Raciocínio Verbal (prova RV) é composta por 25 itens envolvendo analogia, como na prova de raciocínio abstrato, contudo entre palavras. A relação analógica existente entre um primeiro par de palavras deverá ser descoberta e aplicada de forma que se identifique a quarta palavra entre as cinco alternativas de respostas que mantenha a mesma relação com uma terceira apresentada. O tempo limite é de 10 minutos.

A prova de Raciocínio Numérico (prova RN) apresenta 20 itens. Na forma de séries de números 1 lineares ou alternadas, em que o sujeito deve descobrir a relação aritmética que rege as progressões nas séries e aplicá-la, respondendo quais seriam os 2 últimos números que completariam a série. O tempo limite é de 18 minutos.

O BPR-5 é composto pelos seguintes materiais: manual de aplicação, caderno de aplicação, folhas de respostas e crivos de avaliação. A forma de aplicação pode ser individual e/ou coletiva, e o tempo é de aproximadamente uma hora e 40 minutos para as cinco provas. Neste caso, então, em que foram aplicadas apenas três provas, o tempo previsto para a aplicação foi de aproximadamente 40 minutos. A pontuação bruta do BRP-5 é transformada em medida relativa (percentil).

O inventário PSI, de oitenta itens, foi elaborado para ajudar as pessoas a avaliarem o foco e o padrão de sua própria espiritualidade. Na presente pesquisa, foi utilizada apenas parte desses itens, compondo um inventário de 49 itens, devido a estes serem os que estão incluídos no quadro de aferição de resultados; os outros 31, segundo Wolman (2001), estiveram bem próximos de alcançar status de fator, mas ainda estão sendo pes- 
quisados e, desse modo, não foram empregados nesta pesquisa.

Podem-se identificar sete fatores que juntos compreendem aspectos do comportamento e da experiência espiritual: divindade, diligência, intelectualidade, comunidade, percepção extra-sensorial, espiritualidade na infância e trauma.

As categorias de respostas estão dispostas em uma escala de quatro pontos: nunca $=1$; raramente $=2$; frequentemente $=3$; quase sempre $=4$. Para marcar os pontos do PSI, somam-se os pontos para cada item em cada fator. Divide-se esse número de dois dígitos por sete. Esse número é o resultado do fator. Em seguida, localiza-se o resultado do fator na grade correspondente para determinar se o resultado está descrito como alto, moderado ou baixo. Resultados altos não são necessariamente bons; resultados baixos não são necessariamente ruins. Os resultados localizam apenas o perfil em relação a outras pessoas (americanos em sua maioria) que já responderam ao inventário, possibilitando identificar os padrões que regem a espiritualidade do colaborador. Novamente vale ressaltar que o instrumento não apresenta evidências de validade para a realidade brasileira, não havendo tabelas normativas nacionais para a interpretação dos dados. Assim, o instrumento é empregado na presente pesquisa de forma exploratória.

\section{Procedimentos}

A coleta foi realizada de forma coletiva em sala de aula. Inicialmente estabeleceu-se um bom rapport entre os pesquisadores e os colaboradores, em seguida foram transmitidos aos colaboradores os objetivos do estudo. Cabe destacar que este estudo foi aprovado pelo comitê de ética da instituição à qual está vinculado e está em consonância com o que preconiza a Resolução 196/96 do Conselho Nacional de Saúde.

O teste BPR-5 foi aplicado conforme as instruções de seu respectivo manual, com tempo previsto de aproximadamente 40 minutos para sua aplicação. Após o término da aplicação do BPR-5, foi aplicado o inventário PSI, tendo o aplicador lido as instruções para os colaboradores. Esse inventário não tem um tempo pré-determinado para sua realização, sendo permitido que cada colaborador responda às questões em seu tempo. Assim, de modo geral, cada participante levou de 5 a 10 minutos para preencher o instrumento.

\section{Resultados}

Os dados foram organizados em planilha Excele submetidos à estatística descritiva e inferencial, conforme os objetivos deste estudo. Os dados obtidos nos Raciocínios abstrato, verbal e numérico estão apresentados na Tabela 1.

Na Tabela 1, observa-se que os valores médios do percentil obtidos pelos participantes nos três raciocínios analisados ficaram baixos. Esse resultado revela que os respondentes não se saíram muito bem, sendo a melhor pontuação obtida no raciocínio verbal.

Tabela 1. Distribuição da pontuação obtida pelos participantes nos raciocínios abstrato, verbal e numérico.

\begin{tabular}{|c|c|c|c|c|c|c|}
\hline & \multirow{2}{*}{ Raciocínios } & \multirow{2}{*}{ Características } & \multirow{2}{*}{$\begin{array}{l}\text { Total de pontos } \\
\text { possíveis }\end{array}$} & \multicolumn{3}{|c|}{ Percentis e pontos correspondentes } \\
\hline & & & & Média & Mínimo & Máximo \\
\hline & \multirow[t]{2}{*}{ Abstrato } & Associa-se principalmente à inteligência fluida, definida como & & 31,2 & 0 & 93 \\
\hline 즌 & & $\begin{array}{l}\text { capacidade de raciocinar em situações novas, criar conceitos e } \\
\text { compreender implicações }\end{array}$ & 25 & 16 & & 22 \\
\hline \multirow{3}{*}{ 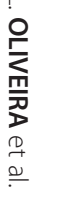 } & \multirow[t]{2}{*}{ Verbal } & Associa-se à inteligência fluida e à inteligência cristalizada, definida & & 41,6 & 2 & 99 \\
\hline & & $\begin{array}{l}\text { como extensão e profundidade do conhecimento verbal voca- } \\
\text { bular e capacidade de raciocinar utilizando conceitos previamente } \\
\text { aprendidos }\end{array}$ & 25 & 17 & 7 & 23 \\
\hline & \multirow[t]{2}{*}{ Numérico } & Associa-se em parte à inteligência fluida e à habilidade quantita- & & 32,0 & 3 & 99 \\
\hline 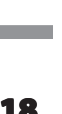 & & $\begin{array}{l}\text { tiva, como o entendimento de conceitos quantitativos básicos, } \\
\text { como soma, subtração, multiplicação e divisão e manipulação } \\
\text { de símbolos numéricos }\end{array}$ & 20 & 11 & 2 & 23 \\
\hline
\end{tabular}


Os dados da média de pontos em cada subescala do PSI podem ser vistos na Tabela 2, que apresenta a média, o desvio-padrão, a pontuação mínima e máxima.

Os dados mostram que os participantes pontuaram mais no fator divindade. Cabe lembrar que resultados altos ou baixos não denotam aspecto positivo ou negativo, uma vez que o PSI trata de traçar um perfil dos participantes.

Recorreu-se à correlação de Pearson para encontrar possíveis relações entre raciocínio abstrato, raciocínio verbal e raciocínio numérico e os sete fatores da escala PSI. No que se refere à relação entre o raciocínio abstrato e o fator 1 - divindade-do Psychomatrix Spirituality Inventory, os dados evidenciaram correlação estatisticamente significativa negativa, considerando $r=-0,359$ e $p=0,017$.

Quanto à relação entre o raciocínio abstrato e o fator 2 - diligência -, novamente recorreu-se à correlação de Pearson. Os dados também evidenciaram correlação estatisticamente significativa negativa, considerando $r=-0,414$ e $p=0,005$.

Tabela 2. Distribuição dos resultados relativos à média de pontos, desvio-padrão e pontuação mínima e máxima em cada subescala.

\begin{tabular}{|c|c|c|c|c|c|}
\hline \multirow{2}{*}{ Subescalas do PSI } & \multirow{2}{*}{ Características } & \multirow{2}{*}{ M } & \multirow{2}{*}{ DP } & \multicolumn{2}{|c|}{ Pontuação } \\
\hline & & & & Mínima & Máxima \\
\hline Fator 1 - Divindade & $\begin{array}{l}\text { Noção de conexão com Deus oufonte de energia } \\
\text { divina }\end{array}$ & 3,1 & 0,5 & 1,2 & 4,0 \\
\hline Fator 2 - Diligência & Consciência da interconexão entre corpo e mente & 2,2 & 0,4 & 1,4 & 3,2 \\
\hline Fator 3 - Intelectualidade & $\begin{array}{l}\text { Processo cognitivo, leitura e discussão de textos } \\
\text { sagrados }\end{array}$ & 2,0 & 0,5 & 1,0 & 3,7 \\
\hline Fator 4 - Comunidade & $\begin{array}{l}\text { Prática da espiritualidade; ações como caridade } \\
\text { ou política. }\end{array}$ & 1,8 & 0,5 & 1,0 & 3,2 \\
\hline Fator 5 - Percepção extrassensorial & $\begin{array}{l}\text { Sentimentos e percepções associados à espiri- } \\
\text { tualidade }\end{array}$ & 2,6 & 0,4 & 1,7 & 3,5 \\
\hline Fator 6 - Espiritualidade na infância & $\begin{array}{l}\text { Associação histórica e pessoal à espiritualidade } \\
\text { por meio de ações e tradições familiares }\end{array}$ & 2,0 & 0,4 & 1,2 & 3,2 \\
\hline Fator 7 - Trauma & $\begin{array}{l}\text { Experiências com doenças ou traumas, físicos ou } \\
\text { emocionais, vividos pela pessoa }\end{array}$ & 2,6 & 0,4 & 2 & 3 \\
\hline
\end{tabular}

PSI: Psychomatrix Spiritiality Inventory; M: Média; DP: Desvio-Padrão.

Tabela 3. Valores de re $p$ entre os raciocínios verbal, numérico e abstrato e os fatores da inteligência espiritual.

\begin{tabular}{|c|c|c|c|}
\hline \multirow{2}{*}{ Inteligência espiritual } & \multicolumn{3}{|c|}{ Raciocínios (Valores $r$ e $p$ ) } \\
\hline & Verbal & Numérico & Abstrato \\
\hline \multirow[t]{2}{*}{ Fator 1 - Divindade } & $-0,232$ & $-0,026$ & $-0,359$ \\
\hline & 0,130 & 0,868 & 0,017 \\
\hline \multirow[t]{2}{*}{ Fator 2 - Diligência } & $-0,175$ & $-0,31$ & $-0,414$ \\
\hline & 0,256 & 0,841 & 0,005 \\
\hline \multirow[t]{2}{*}{ Fator 3 - Intelectualidade } & $-0,050$ & $-0,057$ & $-0,206$ \\
\hline & 0,749 & 0,713 & 0,179 \\
\hline \multirow[t]{2}{*}{ Fator 4 - Comunidade } & 0,038 & 0,229 & $-0,132$ \\
\hline & 0,806 & 0,134 & 0,392 \\
\hline \multirow[t]{2}{*}{ Fator 5 - Percepção extrassensorial } & $-0,051$ & 0,176 & $-0,041$ \\
\hline & 0,744 & 0,253 & 0,794 \\
\hline \multirow[t]{2}{*}{ Fator 6 - Espiritualidade na infância } & 0,038 & 0,229 & $-0,132$ \\
\hline & 0,806 & 0,134 & 0,392 \\
\hline \multirow[t]{2}{*}{ Fator 7 - Trauma } & 0,429 & 0,146 & 0,054 \\
\hline & 0,004 & 0,345 & 0,727 \\
\hline
\end{tabular}


Tabela 4. Distribuição das intercorrelações das subescalas do Psychomatrix Spiritiality Inventory, valores de $r$ e $p$.

\begin{tabular}{|c|c|c|c|c|c|c|c|c|}
\hline & & F1 & F2 & F3 & F4 & F5 & F6 & F7 \\
\hline \multirow[t]{2}{*}{ F1 } & $r$ & 1 & 0,399 & 0,292 & 0,482 & 0,399 & 0,154 & 0,314 \\
\hline & $p$ & 0,000 & 0,007 & 0,054 & 0,001 & 0,007 & 0,317 & 0,038 \\
\hline \multirow[t]{2}{*}{$F 2$} & $r$ & 0,399 & 1 & 0,494 & 0,529 & 0,325 & 0,319 & 0,103 \\
\hline & $p$ & 0,007 & 0,000 & 0,001 & 0,000 & 0,031 & 0,035 & 0,507 \\
\hline \multirow[t]{2}{*}{ F3 } & $r$ & 0,292 & 0,494 & 1 & 0,404 & 0,370 & 0,501 & $-0,020$ \\
\hline & $p$ & 0,054 & 0,001 & 0,000 & 0,007 & 0,013 & 0,001 & 0,900 \\
\hline \multirow[t]{2}{*}{ F4 } & $r$ & 0,482 & 0,529 & 0,404 & 1 & 0,408 & 0,380 & 0,356 \\
\hline & p & 0,001 & 0,000 & 0,007 & 0,000 & 0,006 & 0,011 & 0,018 \\
\hline \multirow[t]{2}{*}{ F5 } & $r$ & 0,399 & 0,325 & 0,370 & 0,408 & 1 & 0,307 & 0,089 \\
\hline & $p$ & 0,007 & 0,031 & 0,013 & 0,006 & 0,000 & 0,043 & 0,567 \\
\hline \multirow[t]{2}{*}{ F6 } & $r$ & 0,154 & 0,319 & 0,501 & 0,380 & 0,307 & 1 & 0,093 \\
\hline & $p$ & 0,317 & 0,035 & 0,001 & 0,011 & 0,043 & 0,000 & 0,547 \\
\hline \multirow[t]{2}{*}{ F7 } & $r$ & 0,314 & 0,103 & $-0,020$ & 0,356 & 0,089 & 0,093 & 1 \\
\hline & $p$ & 0,038 & 0,507 & 0,900 & 0,018 & 0,567 & 0,547 & 0,000 \\
\hline
\end{tabular}

Ao se considerarem os raciocínios verbal e numérico e os fatores da escala do PSI (fator 1 - divindade; fator 2 - diligência; fator 3 - intelectualidade; fator 4 - comunidade; fator 5 - percepção extra-sensorial; fator 6 - espiritualidade na infância e fator 7 - trauma), não foi possível observar nenhuma relação estatisticamente significativa, exceto entre o raciocínio verbal e o fator 7 - trauma, conforme consta na (Tabela 3). Observa-se que o raciocínio abstrato somente se relacionou aos fatores 1 - divindade e 2 - diligência. Pode-se observar Tabela 3 os valores de re $p$, considerando os raciocínios verbal, numérico e abstrato e os fatores ora citados como representantes da inteligência espiritual.

Na Tabela 3, evidencia-se que os raciocínios verbal, numérico e abstrato, de modo geral, não tiveram correlação com os fatores da inteligência espiritual. Assim, ao se considerarem todas as possibilidades de correlação, esta somente ocorreu entre os raciocínios abstrato e fatores 1 e 2 da inteligência espiritual e o verbal e o fator 7 da inteligência espiritual.

A correlação de Pearson também foi utilizada para levantar de forma exploratória a possível correlação dos fatores do PSI entre si. A Tabela 4 apresenta os dados obtidos.

\section{Discussão e Conclusão}

Esta pesquisa não focou a correlação entre os construtos de inteligência geral e inteligência espiritual;

20 buscou, contudo, explorar a inteligência espiritual e os raciocínios abstrato, verbal e numérico. Assim, constatou-se que somente o raciocínio abstrato apresentou uma correlação negativa e significativa com os fatores divindade e diligência; os demais raciocínios não apresentaram nenhuma relação, exceto o raciocínio verbal e o fator trauma.

Na sequência, serão tecidas algumas considerações, que servirão mais para desconfiar do dado obtido, por assim dizer, do que propriamente como evidências concretas da relação entre habilidade cognitiva e inteligência espiritual.

Assim, os resultados da presente pesquisa, ainda que exploratórios, parecem corroborar com a consideração de Lowen (1990), pois quanto mais uma pessoa está desconectada de seu corpo, maior a probabilidade de ela ter se tornado uma pessoa puramente intelectual com atitudes superficiais perante a vida. Para o autor, espiritualidade significa a integração entre corpo e mente. Sendo assim, hipotetiza-se que, quanto maior a habilidade de raciocínio intelectual, no caso representado de forma mais concreta pelos raciocínios verbal e numérico, menor a consciência ou concepção de algo transcendental permeando a vida do indivíduo. Supostamente isso mostra que se trata de pessoas pragmáticas, isto é, pessoas práticas e objetivas que não estão preocupadas em atribuir o sentindo da vida a uma força superior, a não ser a si próprias. Essa característica talvez possa ser mais bem compreendida, sobretudo, quando se considera que se trata de universitários, pessoas que, possivelmente, estão em busca de uma visão mais 
crítica e científica dos fenômenos. Para entender melhor esse dado, remete-se à pontuação dos participantes nos raciocínios abstrato, verbal e numérico: em todos os casos os estudantes conseguiram apresentar um bom número de pontos. Isso demonstraria que se trata de pessoas intelectualizadas? Essa questão, evidentemente, não pode ser respondida afirmativamente somente com os dados exploratórios provenientes da presente investigação, o que reforça a necessidade de realização de estudos futuros.

Wolman (2001) conceitua a inteligência espiritual como a busca pelo significado da vida ou a conexão à energia divina como vivência desses aspectos no decorrer da vida. Pondera-se que não se pretende afirmar que pessoas inteligentes com boa capacidade de abstração são menos espiritualizadas, e sim explicitar os resultados obtidos: as pessoas que demonstraram altas habilidades nos fatores divindade e diligência também foram aquelas que tiveram um baixo desempenho no raciocínio abstrato. Em linhas gerais, hipotetiza-se, ponderando-se a necessidade de maior aprofundamento e evidências, que, quanto maior a capacidade de raciocinar em situações novas, criar conceitos e compreender implicações, menor a capacidade da noção de Deus ou outra fonte de explicação divina e a consciência da conexão entre corpo, mente e espiritualidade. Assim, presume-se que pessoas que conseguem criar novas possibilidades e que apresentam maior compreensão das implicações de suas atitudes também consigam, possivelmente, encontrar mais facilmente saídas para seus problemas, não recorrendo, desse modo, a alguma outra ajuda ou conforto, como é o caso da espiritualidade.

Todavia, esse dado deve ser visto com cautela, mesmo porque Wolman (2001) deixa muito claro que um resultado baixo em qualquer um dos fatores do inventário de espiritualidade não significa que a pessoa seja menos espiritualizada. O autor defende que a pessoa provavelmente nesse momento de sua vida não está praticando sua espiritualidade.

É fundamental esclarecer que o PSI apresenta um construto subjacente por deveras subjetivo, e, como não há evidência de sua validade no contexto nacional, fica difícil associá-lo às habilidades cognitivas, como também não é possível confirmá-lo como medida de inteligência espiritual. Este estudo, portanto, apenas cuidou de explorar o PSI, não descartando a neces- sidade de investigações futuras mais aprofundadas que primem por buscar a validade e a normatização do instrumento para o contexto nacional, especialmente conferindo a possível evidência do construto inteligência espiritual.

Elias e Giglio (2001) e Moreira-Almeida et al. (2006) também defendem a ideia de que espiritualidade é uma atitude humana, um movimento interno ou o amadurecimento da personalidade. Portanto, algo que pouco tem a ver com habilidade lógico-matemática, expressão verbal, ortografia, ou seja, com a capacidade puramente intelectual. Como já foi mencionado, neste estudo, os participantes apresentaram um desempenho que pode ser considerado bom nos raciocínios que revelam essas habilidades. Camon et al. (2002) relacionam a capacidade de transcendência à possibilidade pessoal de o humano buscar compreender seus limites pessoais. Por isso, apontam que, querendo ou não, todas as pessoas praticam a espiritualidade de alguma forma, porque estão sempre em busca da evolução da própria condição humana.

Segundo Baptista e Campos (2007), uma das questões da atualidade é justamente esta: até que ponto o rigoroso saber científico traz respostas ao desconforto humano em relação a sua incessante busca pela identidade? Respostas para 'Quem sou? De onde vim? Para onde vou?' ainda continuam fazendo parte da inquietação da humanidade, construindo muitos conflitos psicológicos e doenças mentais, ou seja, aumentando cada vez mais a procura pelos serviços de psicologia. Entretanto, estaria a psicologia preparada para enfrentar os grandes desafios contemporâneos, como o de proporcionar melhor compreensão do ser biopsicossocial no qual está incluída a concepção de espiritualidade?

Esta pesquisa objetivou, portanto, explorar a inteligência espiritual e os raciocínios abstrato, verbal e numérico, tentando integrar ambos os conhecimentos e, assim, levantar novas possibilidades para a prática profissional do psicólogo. Segundo Primi (2003), esse é um grande desafio que a área da avaliação psicológica vem conseguindo superar, o de explorar e operacionalizar as teorias psicológicas com o rigor científico exigido. Essa é uma prática que visa à construção de novos instrumentos de medidas para melhorar as condições de trabalho do psicólogo e fazê-lo conquistar o fato de que realmente está praticando ciência. Atualmente, a 
sociedade espera provas concretas de que a prestação de serviço de psicologia funcione. Como defendem Camon et al. (2002), espiritualidade também faz parte das preocupações e dos direcionamentos do homem contemporâneo.

Wolman (2001) enfatiza que sua pesquisa sobre inteligência espiritual surgiu justamente em função dessa mesma necessidade. Na presente pesquisa, com a análise da correlação de Pearson, observou-se que, mesmo na população brasileira, e, ainda, considerando que se trata de uma amostra pequena, as intercorrelações entre os sete fatores propostos por Wolman (2001) se confirmaram. Essa evidência chama a atenção para a necessidade de estudos mais focais, como uma análise fatorial exploratória ou a aplicação da teoria de resposta ao item, pois uma amostra maior e mais diversificada poderia trazer maior consistência ao instrumento bem como corroborar para estudos de sua validação para a realidade brasileira.

\section{Referências}

Almeida, L. S. (1988). O raciocínio: delimitação do conceito e sua avaliação. In L. S. Almeida (Org.), O raciocínio diferencial dos jovens (pp.23-27). Porto: Instituto Nacional de Investigação Científica.

Angelini, A. L., Alves, I. C. B., Custódio, E. M., Duarte, W. F., \& Duarte, J. L. M. (1999). Manual: matrizes coloridas de Raven, escala especial. São Paulo: Centro Editor de Teste e Pesquisas em Psicologia.

Antunes, C. (2003). As inteligências múltiplas e seus estímulos (1 1 a ed.). São Paulo: Papirus.

Baptista, A. S. D. (2004). Estudo sobre as práticas religiosas e suas relação com a saúde mental de idosos: um estudo na comunidade. Tese de doutorado não-publicada, Universidade Federal de São Paulo.

Baptista, M. N., \& Campos, C. D. (2007). Metodologias de pesquisa emciências: uma análise quantitativa equalitativa. Rio de Janeiro: LCT.

Benzeery, D. F. (2001). Competências do administrador moderno sob a luz da teoria das liteligências múltiplas. Revista Brasileira de Administração, 11 (34), 13-16.

Camon, V. A. A., Perez-Ramos, A. M. Q., Maia, E. M. C., Roth, M. C., Maciel, S. C., \& Campos, T. C. P. (2002). Novos rumos na psicologia da saúde. São Paulo: Pioneira.

Connelly, R., \& Light, K. (2003). Exploring the new frontier of spirituality in health care: identifying the dangers. Journal of Religion and Health, 42 (1), 35-46.

Conselho Nacional de Saúde. Resolução 196/96. Diretrizes e normas regulamentadoras de pesquisa. Recuperado outubro 19, 2005, disponível em <http://www.conselho. saude.gov.br>.
Elias, A. C. A., \& Giglio, J. S. (2001). A questão da espiritualidade na realidade hospitalar: o psicólogo e a dimensão espiritual do paciente. Estudos de Psicologia (Campinas), 18 (3), 23-32.

Fleck, M. P. A., Borges, Z. N., Bolognesi, G., \& Rocha, N. S. (2003). Desenvolvimento do WHOQOL, módulo espiritualidade, religiosidade e crenças pessoais. Revista de Saúde Pública, 37 (4), 446-455.

Gonida, E., Kiosseoglou, G., \& Leondari, A. (2006). Implicit theories of intelligence, perceived academic competence, and school achievement: testing alternative models. American Journal of Psychology, 119 (2), 223-238.

Koenig, H. G. (2001). Religion and medicine II: religion, mental health and related behaviors. The Internation Journal of Psychiatry in Medicine, 31 (1), 97-109

Koenig, H. G., Pargament, K. I., \& Nielsen, J. (1998). Religious coping and health status in medically ill hospitalized older adults. The Journal of Nervous and Mental Disease, 186 (9), 513-521.

Lowen, A. (1990). A espiritualidade do corpo. São Paulo: Cultrix.

Moreira-Almeida, A., Lotufo Neto, F., \& Koenig, H. (2006). Religiosidade e saúde mental: uma revisão. Revista Brasileira de Psiquiatria, 28 (3), 242-250.

Okada, M. (1949). O homem, a saúde e a felicidade. São Paulo: Yangraf.

Panzarini, R. G., \& Bandeira, D. R. (2005). Escala de coping religioso-espiritual (Escala CRE): elaboração e validação de construto. Psicologia em Estudo, 10 (3), 507-516.

Pasquali, L. (2005). A sociedade não aceita mais qualquer coisa. Revista Diálogos, 3, 6-10.

Primi, R. (1998). Desenvolvimento de um instrumento informatizado para avaliação do raciocínio analítico. Tese de doutorado não-publicada Programa de Pós-Graduação em Psicologia, Universidade de São Paulo.

Primi, R., \& Almeida, L. S. (2000). Bateria de provas de raciocínio: manual técnico. São Paulo: Casa do Psicólogo.

Primi, R. (2003). Inteligência: avanços nos modelos teóricos e nos instrumentos de medida. Avaliação Psicológica, 1 (2), 67-77.

Primi, R., \& Ferreira, M. C. (2005). Desmistificando bolas de cristal. Revista Diálogos, 3, 19-22.

Sailor, K. M., \& Abreu, Y. (2005). The nature of memory errors for verbally quantified information. American Journal of Psychology, 118 (2), 235-250.

Sisto, F. F., Santos, A. A. A., \& Noronha, A. P. P. (2005). Inteligência. Manuscrito não-publicado, Programa de Pós-Graduação em Psicologia, Universidade São Francisco, Itatiba.

Spearman, C. (1904). General intelligence, objectively determined and measured. American Journal of Psychology, 15 (2), 201-293.

Spearman, C. (1927). Las habilidades del hombre: su naturaleza y medición. Buenos Aires: Paidós.

Wolman, R. N. (2001). Inteligência espiritual. Rio de Janeiro: Ediouro.

Recebido em: 15/2/2008

Versão final reapresentada em: 12/9/2011

Aprovado em: 11/10/2011 